\title{
Research on Distribution Network Full Cost-Benefit Optimization Considering Different Renewable Energy Penetration
}

\author{
Tanzhong Fu ${ }^{1,2,3}$, Yu Xue ${ }^{1, *}$, Tancai Xia ${ }^{1}$, Wang Jing ${ }^{1}$ and De Gejirifu ${ }^{1}$ \\ ${ }^{1}$ North China Electric Power University, Beijing, 102206, China \\ ${ }^{2}$ Yan'an University, Yan'an, 716000, China \\ ${ }^{3}$ Beijing Energy Development Research Center, Beijing, 102206, China \\ *Corresponding Author: Yu Xue. Email: yx_2018n@163.com \\ Received: 21 May 2020; Accepted: 10 July 2020
}

\begin{abstract}
To further study the impact of renewable energy penetration on the technical transformation of distribution networks. Based on the output power characteristics of wind power and photovoltaics, a renewable energy grid-connected capacity model and a distribution network full cost-benefit model were constructed. Based on this, to maximize the comprehensive income of the distribution network and the renewable energy penetration rate, to establish the technical reform optimization model and search for the optimal solution through the improved NSGA-II algorithm. Finally, the effectiveness of the proposed model was verified by setting up three scenarios of simultaneous wind power, grid-connected wind power, grid-connected wind power, and grid-connected photovoltaic power.
\end{abstract}

Keywords: Renewable energy; full cost-benefit; technical transformation of distribution network

\section{Introduction}

With the gradual deepening of China's electricity market reform and the orderly development of renewable energy, the contradiction between the operation cost and benefit of the distribution network transformation infiltrated by clean energy is an urgent research topic. Regional power distribution network, as an essential intermediate link between the connected users and the penetration of renewable energy, should gradually strengthen the acceptance of clean energy while ensuring the power supply quality, security, and stability of the power grid, and reasonably reduce the cost burden of the distribution network caused by the penetration of renewable energy.

At present, the research on the cost of the distribution network is mainly focused on the cost control and optimization of the construction project of the distribution network and the cost allocation method of distribution networks. Literature [1] proposed an active distribution network cost allocation method based on the distribution factor method (GLDF). Literature [2] conducted cost supervision and control of distribution network engineering through improved net value method (EVM), which enhanced project cost supervision and control. Literature [3], Under the premise of ensuring power quality, the calculation of different compensation schemes by introducing full life cycle cost shows that reactive power

This work is licensed under a Creative Commons Attribution 4.0 International License, which permits unrestricted use, distribution, and reproduction in any medium, provided the original work is properly cited. 
optimization that takes full life cycle cost into account is more effective in practice. Literature [4] established a model of life-cycle costs and benefits and proposed a strategy of cost reduction and optimal allocation by combining the genetic and simulated annealing algorithms used in the inner and outer layers. In [5], the sensitivity method and marginal network loss coefficient method are used to calculate the node marginal capacity cost of distribution network more accurately. Literature [6-7] made an in-depth study of the reasonable allocation of grid project costs based on the electricity transmission and distribution price. Literature [8] established the life efficiency index model based on the total life-cycle cost of the transformer and used the rhododendron algorithm for parameter optimization. In [9-12], considering the reactive power cost of the fan and taking the safety and stability of the distribution network and the lowest cost as one of the objectives, a multi-objective function was established to solve the problem.

The related researches on the renewable energy permeable distribution network pay more attention to the security and stability of the network. Literature [13], combined with the domestic power system construction environment and demand, put forward a method for determining the reasonable renewable energy penetration rate. Literature [14] considered the influence of wind power grid entry on the power system's safety and stability and the allocation of reserve capacity. It proposed a reserve capacity optimization model with the desired minimum of bilateral reserve cost as the objective function. Literature [15-17] incorporated wind power cost and photovoltaic cost into the model construction as parameters. Literature [18] analyzed the relationship between the increase of intermittent renewable energy access ratio and system reserve capacity. It proposed the provision of reserve service by a non-rotating reserve with flexible adjustment performance. Literature [19-20] considered the impact of output fluctuation of renewable energy on system operation economy, reliability, and environmental benefits. Literature [21] established an optimization model of a distributed energy system based on mixed-integer linear programming and obtained the system's optimal configuration and operation mode.

The above study did not consider the balance between the cost of operation and maintenance of the regional distribution network to accept renewable energy and the benefits generated by the infiltration of renewable energy. In this paper, the full cost-benefit model of the distribution network under the penetration of renewable energy is proposed in combination with the cost-benefit study of the distribution network and the research on the standby capacity of the distribution network under the penetration of renewable energy. An optimization model for the technical transformation of the distribution network under the infiltration of renewable energy was proposed given the cost generation and subsequent benefits of the technical transformation of the distribution network under the infiltration of renewable energy and used the improved NSGA-II algorithm to solve the model and verify the validity of the model. The innovation of this paper is as follows: 1. Consider the feasibility and optimization measures of different proportions of renewable energy connected to the grid from the perspective of distribution network cost; 2. According to the characteristics of the model, the improved NSGA-II algorithm is adopted to solve Improve computing efficiency.

\section{The Full Cost-Benefit Model of Distribution Network under the Penetration of Renewable Energy}

With the penetration of renewable energy into the distribution network, due to the volatility and randomness of its output, the technical transformation of the equipment and lines in the distribution network leads to the rise in the cost of the distribution network. Thus, the full cost-benefit model of distribution network under the penetration of renewable energy is constructed.

\subsection{Renewable Energy Grid Capacity Allocation Model}

The reserve ensures that the distribution network can operate normally and stably in the case of random shutdown of renewable energy output and load fluctuation, to realize the balance between load and power generation and prevent chain accidents and large-scale power failure. Reserve is divided into load reserve, 
maintenance reserve, and failure reserve, and its capacity setting is closely related to the prediction accuracy of wind power and photovoltaic output. The prediction deviation model of wind power and photovoltaic is as follows:

(1) Wind power output prediction deviation model

The wind power output prediction model is constructed based on the variable speed constant frequency wind turbine, as shown in Eq. (1):

$P_{w}=\left\{\begin{array}{cc}0 & 0<v<v_{\text {in }}, v>v_{\text {out }} \\ \frac{P_{e} v_{\text {in }}^{3}}{v_{\text {in }}^{3}-v_{e}^{3}+\frac{P_{e} v_{\text {real }}^{3}}{v_{e}^{3}-v_{\text {in }}^{3}}} & v_{\text {in }}<v<v \\ P_{e} & v_{e}<v<v_{\text {out }}\end{array}\right.$

where, $P_{e}$ represents the rated power of the wind turbine; $v_{i n}, v_{\text {out }}, v_{e}$ represent the cut-in wind speed, cut-out wind speed and rated wind speed of the wind turbine respectively, $v_{\text {real }}$ represents actual wind speed. Based on the wind power output prediction model, it can be concluded that the wind turbines follow the twoparameter Weibull distribution, as shown in formula (2):

$f(v)=\frac{b}{a}\left(\frac{v_{\text {real }}}{a}\right)^{b-1} e^{-\left(\frac{v}{a}\right)^{b}}$

where, $a$ and $b$ represent scale parameter and shape parameter respectively. The range of shape parameters is $[2.8,3.3]$. The scale parameters and shape parameters are obtained according to the historical Weibull distribution.

The wind power output prediction model was built based on the variable speed and constant frequency fan. The error of wind power unit output prediction was slower than the normal distribution curve and faster than the Laplace distribution curve. The error prediction model of wind turbine output is constructed by combining normal distribution function and Laplace function:

$f_{\text {sum }}(\Delta w)=\mathrm{C}_{1} \frac{1}{\theta \sqrt{2 \pi}} e^{\left[-\frac{(\Delta w-u)^{2}}{2 \theta^{2}}\right]}+\mathrm{C}_{2} \frac{1}{2 a} e^{-\frac{|\Delta w-u|}{2 \theta^{2}}}$

where, $f_{\text {sum }}(\Delta w)$ is the mixed distribution function; $u$ is the mathematical expectation; $\theta$ is the standard deviation, $\Delta w$ is the wind speed prediction error, and $u$ is the mathematical expectation.

(2) Photovoltaic output deviation prediction model

The influencing factors of photovoltaic radiation intensity include sunshine intensity, sunshine incidence Angle and climate environment, etc. The daily radiation amount can be fitted according to the distribution of $\beta$. The probability density function of photovoltaic power generation and the output prediction error of the photovoltaic power group are shown in Eq. (4):

$$
\left\{\begin{array}{c}
\frac{\Gamma(\lambda+\eta)}{\Gamma(\lambda) \Gamma(\eta)}\left(\frac{P_{p v}}{S \cdot \beta \cdot R}\right)^{\lambda-1}\left(1-\frac{P_{p v}}{S \cdot \beta \cdot R}\right)^{\eta-1} \\
f(\Delta p v)=\frac{1}{\sqrt{2 \pi} \delta} e^{-\frac{x^{2}}{2 \delta^{2} \Delta p v}}
\end{array}\right.
$$

where, $S$ and $\beta$ are respectively the area and conversion efficiency of photovoltaic panel; $R$ is the radiation intensity of sunlight, $\lambda, \eta$ are the fitting parameters of the Beta distribution, $f(\Delta p v)$ is the normal distribution function, $\Delta p v$ is the prediction error of the radiation intensity. 
(3) Configuration of grid-connected capacity of wind power and photovoltaic

Load reserve is related to the maximum load in the distribution network area, and maintenance and emergency reserve are related to the prediction error of wind power and photovoltaic. The capacity configuration is shown in Eq. (5):

$$
\left\{\begin{array}{c}
P_{\text {resever }}=\left(\beta_{\text {load }} P_{\text {peak_load }}+\beta_{\text {main }} \sqrt[2]{f_{\text {sum }}(\Delta w)^{2}+f(\Delta p v)^{2}}+\beta_{\text {acci_load }} \sqrt[2]{f_{\text {sum }}(\Delta w)^{2}+f(\Delta p v)^{2}}\right)^{1+\gamma} \\
\gamma=\frac{Q_{p v}+Q_{w}}{Q_{p v}+Q_{w}+Q_{\text {extra }}}
\end{array}\right.
$$

where, $P_{\text {resever }}$ is the total capacity of renewable energy penetration reserve; $\beta_{\text {load }}$ and $\beta_{\text {main }}$ and $\beta_{\text {acci_load }}$ are respectively load, maintenance and emergency reserve capacity coefficients; $P_{\text {peak_load }}$ is the maximum load in the distribution network area; $\gamma$ is the penetration rate of renewable energy; $Q_{p v}$ is the grid-connected power of photovoltaic; $Q_{w}$ is the grid-connected power of wind power; $Q_{\text {extra }}$ is the output power for other units.

\subsection{Distribution Network Full Cost Model}

After the technical transformation of the distribution network for renewable energy access, the total cost of the distribution network refers to the total cost of the investment and construction of the technical transformation, and the operation, maintenance, maintenance, decommissioning and disposal of these links.

(1) Initial cost of investment

The main part of the initial investment cost is the equipment purchase fee and the construction and installation engineering fee. The equipment purchase fee will be greatly different due to different regions. Regional differentiation can be reflected according to different coefficients. After access to renewable energy, initial investment cost:

$C_{I}=\sum_{i=1}^{n} P_{i} C_{i}+\alpha C_{e c}+P_{\text {reserve }} \overline{C_{\text {reserve }}}$

where, $C_{I}$ is the initial investment cost; $P_{i}$ is the power supply capacity of the i; $C_{i}$ is unit capacity cost of unit $\mathrm{i} ; C_{e c}$ is the construction and installation costs; $\alpha$ is the coefficient of regional difference; $\overline{C_{\text {reserve }}}$ is the cost of per spare capacity.

(2) Maintenance and repair costs

Operation and maintenance maintenance cost mainly consists of operation cost, maintenance cost and failure cost. Operation cost mainly considers line loss; Maintenance costs include routine inspection and overhaul fees; The failure cost includes the failure loss cost, the line loss, the equipment loss, the power network profit loss, the user compensation loss.

$$
\begin{aligned}
C_{O M}= & \sum_{\gamma=1}^{\mathrm{N}}\left(C_{c}+Q_{t} \times \delta \times C_{p}+M_{t} \frac{\sum_{\mathrm{i}=1}^{\mathrm{n}} K^{\left(N, S_{1}, S_{2}, S_{3}\right)}}{n \sum l_{m}^{\left(N, S_{1}, S_{2}, S_{3}\right)}} l_{m}\right. \\
& \left.+G_{t} \frac{\sum_{\mathrm{i}=1}^{\mathrm{n}} K^{\left(N, S_{1}, S_{2}, S_{3}\right)}}{n \sum l_{m}^{\left(N, S_{1}, S_{2}, S_{3}\right)}} l_{m}+Q_{t} \times \delta \times l_{m} \times C_{p}+C_{r c}+C_{o h}\right)^{1+\gamma}
\end{aligned}
$$

where: $C_{O M}$ is the cost of operation maintenance; $C_{c}$ is the equipment and personnel operation and maintenance expenses; $\delta$ is the line loss rate; $C_{p}$ is the network loss price; $M_{t}$ is the maintenance cost of the line; $G_{t}$ is the comprehensive failure loss; $Q_{t}$ is the transmission capacity; $Q_{s}$ is power supply; $l_{m}$ is 
the total length of m-type line; $t$ is the power failure time of a single failure; $m=\left(m_{1}, m_{2} \ldots\right)$ is a set of line types; $n$ is the number of statistical years; $K$ is the failure rate of class $\mathrm{S} ; C_{r c}$ is the cost of inspection and repair; $C_{o h}$ is major repairs; $\mathrm{N}$ is the number of running years.

(3) Decommissioning disposal cost

The cost of decommissioning disposal mainly includes the cost of the equipment disposal and the net residual value of equipment. The influencing factors are the original value of fixed assets, maintenance rate, and equipment utilization rate. The cost of decommissioning disposal is calculated as follows:

$C_{D}=\sum_{i=1}^{n} P_{i} C_{i-t d}\left(1+\beta_{\text {load }}\right)-F_{r} \varphi$

where, $C_{D}$ is the decommissioning disposal cost, $C_{i-t d}$ is the cost to be paid for the dismantling and disposal of unit i, $F_{r}$ is the original value of the equipment, and $\varphi$ is the residual value.

\subsection{Distribution Network Revenue Model}

After the technical transformation of the power grid, the renewable energy is connected to the power distribution network to generate economic and environmental benefits, and the annual cost-benefit model of the power distribution network is built comprehensively:

$F_{\text {eco }}=Q_{p v}\left(P_{n}-P_{p v}\right)+Q_{w}\left(P_{n}-P_{w}\right)+Q_{e x t r a}\left(P_{n}-P_{\text {extra }}\right)+\sum_{i=1}^{I} \sum_{k=1}^{K} v_{k} Q_{i} g_{k}$

where, $F_{\text {eco }}$ is the income after clean energy access; $Q_{p v}, Q_{w}, Q_{e x t r a}$ respectively are power supply of photovoltaic, wind power and other power sources; $P_{p v}, P_{w}, P_{\text {extra }}$ respectively are the grid-connected prices of photovoltaic, wind power and other power sources; $P_{n}$ is the price of electricity for users ; $Q_{i}$ is the electricity supply from the clean energy; $v_{k}$ is the discharge coefficient of the k pollutant; $g_{k}$ is the penalty cost of the k pollutant.

\section{Optimization Model of Technical Transformation of Distribution Network under the Penetration of Renewable Energy}

\subsection{Optimize the Objective Function by Technical Transformation}

The goal of the distribution network optimization is to achieve the maximum comprehensive income of the distribution network, and at the same time ensure the maximum amount of renewable energy connected to the grid, so as to promote the absorption of renewable energy and the optimal technical transformation of the distribution network.

(1) optimization objective function 1: to maximize the comprehensive income of distribution network

Based on the full cost-benefit model of distribution network, the distribution network objective function 1 can be obtained as shown in Eq. (10) below:

$$
\begin{aligned}
\max R_{\text {com }}= & \max \left\{\left[Q_{p v}\left(P_{n}-P_{p v}\right)+Q_{w}\left(P_{n}-P_{w}\right)+Q_{\text {extra }}\left(P_{n}-P_{\text {extra }}\right)\right.\right. \\
& \left.\left.+\sum_{i=1}^{I} \sum_{k=1}^{K} v_{k} Q_{i} g_{k}\right]-\left[C_{I}+C_{O M}+C_{D}\right]\right\}
\end{aligned}
$$


(2) optimization objective function 2: the penetration of renewable energy is the largest

The penetration of renewable energy is the largest, that is, the renewable energy grid-connected volume accounts for the best proportion of the total grid-connected total, and the objective function 2 of the distribution network is constructed as shown in Eq. (11):

$\max \lambda=\max \frac{Q_{p v}+Q_{w}}{Q_{p v}+Q_{w}+Q_{\text {extra }}}$

\subsection{Optimization of Constraints by Technical Modification}

As an investment activity, the optimization of technical transformation is constrained by investment variables. Also, as the regional power supplier, the distribution network is constrained by the relationship between supply and demand and various constraints in the operation process. The specific constraints on the investment variables, the relationship between supply and demand and the operation are shown as follows:

(1) Investment variable constraint

Investment variable constraints include investment amount, load, maintenance and emergency reserve capacity coefficient constraints. Among them, investment restriction means that the initial investment cannot exceed the total investment; Load, operation maintenance coefficient refers to the reserve capacity coefficient has upper and lower limits in order to balance the relationship between the economy of distribution network and the reliability of power supply. The details are shown in Eq. (12) below:

$$
\left\{\begin{array}{c}
0 \leq C_{I} \leq I_{\text {total }} \\
\beta_{m}^{\text {min }} \leq \beta_{m} \leq \beta_{m}^{\text {max }} \\
0 \leq \partial \leq 1
\end{array}\right.
$$

where, $I_{\text {total }}$ is the total investment amount; $\beta_{m}$ is the reserve capacity coefficient of class m, including load, maintenance and emergency reserve capacity coefficient; $\beta_{m}^{\min }$ and $\beta_{m}^{\max }$ is the upper and lower limits of reserve capacity coefficient.

(2) Supply and demand constraints

The supply-demand relationship refers to the capacity of photovoltaic, wind power and other power sources connected to the grid to meet the power demand of regional users, as shown in Eq. (13):

$Q_{p v}+Q_{w}+Q_{\text {extra }} \geq D_{\text {Total }}$

where, $D_{\text {Total }}$ is the electrical energy demand of regional users.

(3) Operation constraints

Operation constraints include wind power, photovoltaic units and distribution network transmission constraints. The details are shown in Eq. (14):

$$
\left\{\begin{array}{l}
Q_{m k}^{\text {min }} \leq Q_{m k} \leq Q_{m k}^{\text {max }} \\
P_{v}^{\text {min }} \leq P_{v} \leq P_{v}^{\text {max }} \\
P_{v}^{\text {start }} \geq P_{v}^{\text {start_min }} \\
P_{v}^{\text {end }} \leq P_{v}^{\text {end_max }}
\end{array}\right.
$$

where, $P_{v}$ is the output value of category $v$ renewable energy generating units, including wind power and photovoltaic units; $P_{v}^{\max }, P_{v}^{\min }$ and $P_{v}^{\max }$ are respectively the upper and lower limits of the output of class $v$ units; $Q_{m k}^{m i n}$ and $Q_{m k}^{m a x}$ and $Q_{m k}$ are respectively the maximum transmission power of the $\mathrm{m}$ line. $P_{v}^{\text {start }}$ 
and $P_{v}^{\text {end }}$ are the starting power and stopping power of the type $v$ unit; $P_{v}^{\text {start }}{ }_{-}$min is the minimum starting power; $P_{v}^{e n d} d_{-} \max$ is the maximum ending power.

\subsection{Model Solving Algorithm}

Distribution network full cost-benefit model contains two optimization objectives and linear constraints, traditional NSGA-II algorithm calculation speed is slow, and the population convergence distribution is uneven, the global search ability is not good. Therefore, after improving the NSGA-II algorithm and obtaining a generation of Pareto non-dominated solutions, the non-dominated solutions are better than global Pareto optimal sets. The local non-dominant solution is added to the optimal global solution set under the current iteration. The adaptive reduction penalty is applied to the local non-dominant solution dominated by the globally optimal set.

(1) Adjust the linear constraint of the objective function:

The linear constraint $f\left(a_{1}, a_{2}, \ldots, a_{k}, \ldots, a_{n}\right)=0, a_{1} \sim a_{k}$ is the optimization variable, $a_{k+1} \sim a_{n}$ can be calculated by the optimization variables and constraints. Let the adjustment range of the linear constraint be $\left(A_{\min } \sim A_{\max }\right)$, and the maximum adjustment number be N. For a set of variables, $a^{0}$, that is $f\left(a^{0}\right)=\Delta m$. If $|\Delta m|<A_{2}$, the approximation is satisfied; otherwise, the adjustment is made. The initial state is $f\left(a^{0}\right)=\Delta m^{0}$, and after $\mathrm{n}$ adjustments, the optimization variable is updated to $a_{i}^{n+1}=\frac{a_{i}^{n}+\Delta m^{n}}{k}, i=1,2, \ldots, k$. Calculate $\mathrm{n}+1$ violations. If the approximation $\Delta m^{n+1}<A_{2}$ is satisfied, the exit adjustment $a_{n+1}$ is taken as the value of the optimization variable; otherwise, the record does not satisfy the constraint.

(2) Penalty function:

Add a penalty term to the objective function to enhance the constraint of variables. Take the penalty factor $C_{1}, C_{2}$, and the total variable after adjustment is $a_{c}$, and the inequality constraint set is $f_{i d}(a) \in\left[m_{\min }, m_{\max }\right]$. If $f_{i d}(a)=m$, then the penalty is:

$G_{i q}\left(f_{i d}\left(a_{c}\right)\right)= \begin{cases}C_{1} \frac{m-m_{\max }}{m_{\max }-m_{\min }} & m>m_{\max } \\ 0 & m_{\min } \leq m \leq m_{\max } \\ C_{2} \frac{m_{\min }-m}{m_{\max }-m_{\min }} & m<m_{\min }\end{cases}$

The model solving process is shown in Fig. 1.

Step 1: Set parameters of the model and input parameters;

Step 2: Initialize the population, set the optimal solution set, and maximize the population algebra;

Step 3: Dynamically adjust the constraint, update the optimal set of the population, and calculate the comprehensive fitness of the population;

Step 4: Quicksort the non-dominant solutions of the two objective functions that are not sufficiently optimal, and update the optimal solution set;

Step 5: Add one to the population algebra to determine whether the maximum population algebra is reached. If yes, go to the next step, otherwise go back to step three;

Step 6: Update the new generation population;

Step 7: Form a new optimal solution set;

Step 8: The output satisfies the optimal of the two objective functions, that is, the parameter value corresponding to the maximum benefit value of the output distribution network and the maximum penetration amount of renewable energy. 


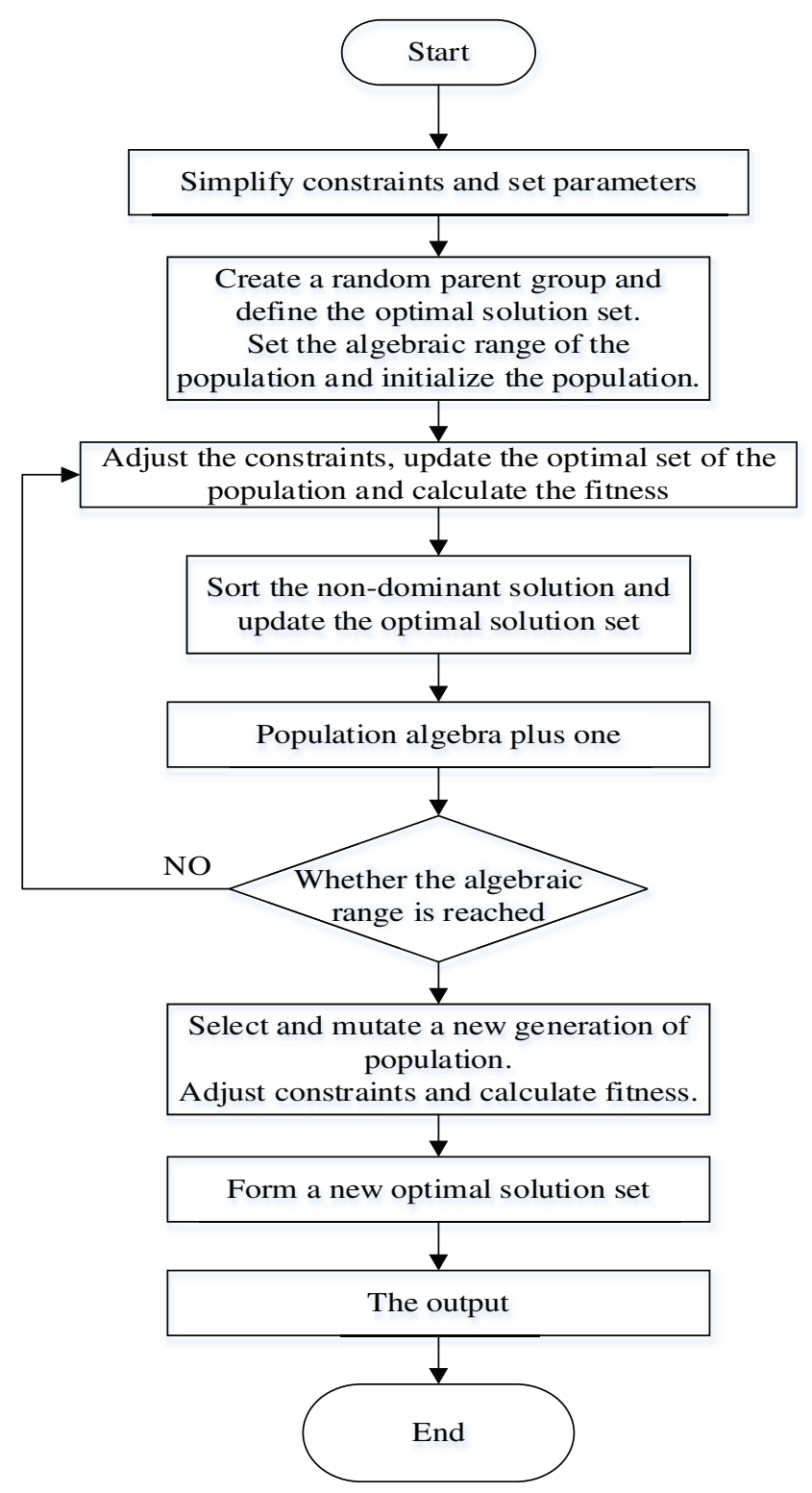

Figure 1: Flow chart of model solution

\section{The Example Analysis}

\subsection{Basic Data}

In order to verify the effectiveness of the proposed model, take the technical transformation of a regional distribution network as an example, the rationality and effectiveness of the proposed optimization model are validated.

It is assumed that the existing circuit equipment of the distribution network cannot meet the requirements of grid connection with renewable energy, technical modification of existing line equipment is required, ensure the quality and reliability of power supply. The technical transformation includes 110 $\mathrm{kV}, 10 \mathrm{kV}, 0.38 \mathrm{kV}$ and $0.22 \mathrm{kV}$ distribution network. The operating parameters of the distribution network are shown in Tab. 1 [13]: 
Table 1: Operation parameters of distribution network

\begin{tabular}{|c|c|c|c|c|c|}
\hline Parameter & $\begin{array}{l}\text { Parameter } \\
\text { value }\end{array}$ & Parameter & $\begin{array}{l}\text { Parameter } \\
\text { value }\end{array}$ & Parameter & $\begin{array}{l}\text { Parameter } \\
\text { value }\end{array}$ \\
\hline$\beta_{\text {load }}$ & $5 \%$ & $\beta_{\text {main }}$ & $7 \%$ & $\beta_{\text {acci_load }}$ & $8 \%$ \\
\hline$C_{i}$ (Ten thousand yuan) & 27 & $\begin{array}{l}\overline{C_{\text {reserve }}} \text { (Ten thousand } \\
\text { yuan) }\end{array}$ & 28 & $P_{p v}($ yuan $/ \mathrm{kWh})$ & 0.55 \\
\hline$P_{w}($ yuan $/ \mathrm{kWh})$ & 0.52 & $P_{\text {extra }}($ yuan $/ \mathrm{kWh})$ & 0.37 & $P_{n}($ yuan $/ \mathrm{kWh})$ & 0.60 \\
\hline $\begin{array}{l}I_{\text {total }}(\text { Ten thousand } \\
\text { yuan) }\end{array}$ & 8000 & $D_{\text {Total }}(\mathrm{MWh})$ & 540 & $\begin{array}{l}g_{c o_{2}}(\text { Ten thousand } \\
\text { yuan/ton) }\end{array}$ & 0.12 \\
\hline $\begin{array}{l}g_{s O_{2}}(\text { Ten thousand } \\
\text { yuan/ton) }\end{array}$ & 0.58 & $\begin{array}{l}g_{N O_{X}}(\text { Ten thousand } \\
\text { yuan/ton) }\end{array}$ & 0.81 & $\begin{array}{l}g_{\text {dust }}(\text { Ten thousand } \\
\text { yuan/ton) }\end{array}$ & 0.25 \\
\hline
\end{tabular}

In order to study the influence of different clean energy on the cost and benefit of the distribution network, three scenarios were set up. In scenario 1, only photovoltaic and thermal power are connected to the grid to meet regional power demand. In Scenario 2, only wind power and thermal power are connected to the grid to meet regional power demand. Scenario 3 is that wind power and photovoltaic grid-connected meet $30 \%$ of regional electricity demand, and thermal power grid-connected meets $70 \%$ of regional electricity demand; Scenario 4 is wind power and photovoltaic grid-connected meets $50 \%$ of regional electricity demand, and thermal power grid-connected meets regional electricity demand $50 \%$ of thermal power grid connection meets $50 \%$ of regional electricity demand. Besides, the improvement of the NSGA-II algorithm, the population size is 100 , the maximum number of iterations is 100 .

\subsection{The Example Results}

(1) Comparative analysis of algorithms

In order to verify the superiority of the NSGA-II algorithm, respectively, using traditional NSGA-II algorithm and improved the NSGA-II algorithm to search the optimal solution model, an iterative results as shown in Fig. 2:

As can be seen from Fig. 2, compared with the traditional NSGA-II algorithm, the improved NSGA algorithm is more efficient in iteration, so the improved NSGA algorithm can be used to search for the global optimal solution to improve the solving rate.

(2) Analysis of optimization results of technical transformation of distribution network

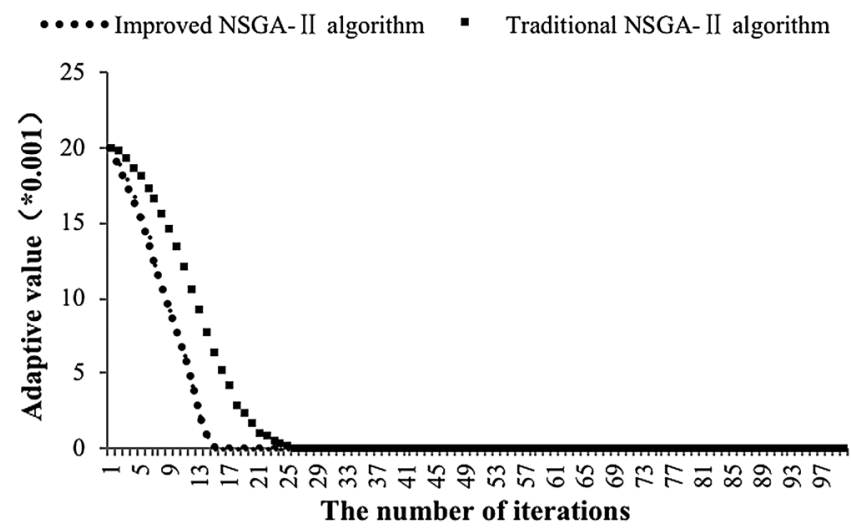

Figure 2: Different algorithm iteration times 


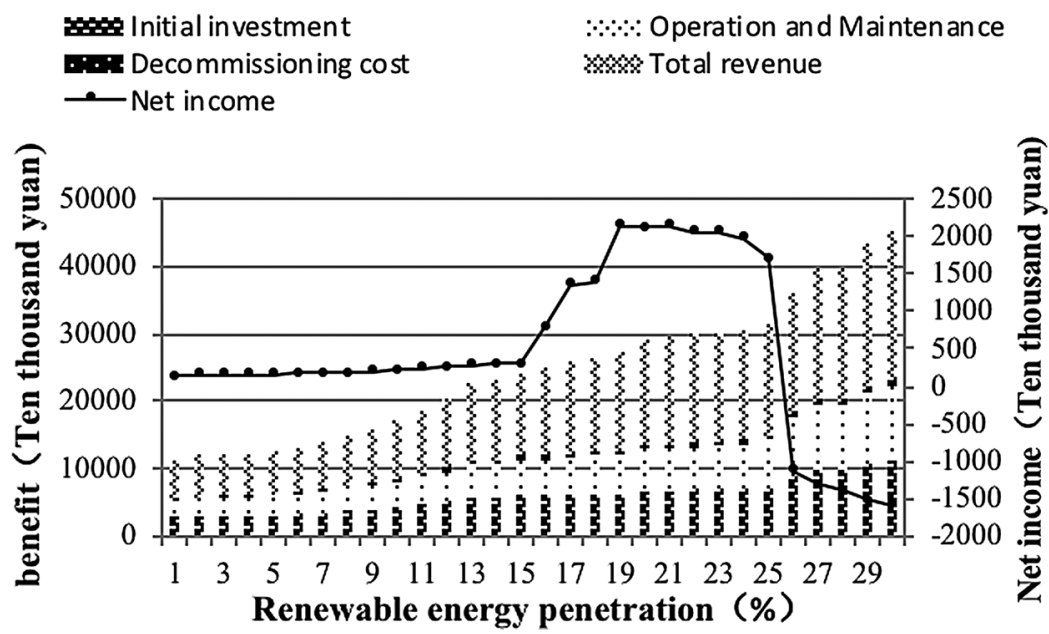

Figure 3: Cost-benefit Scenarios 1 with different permeability

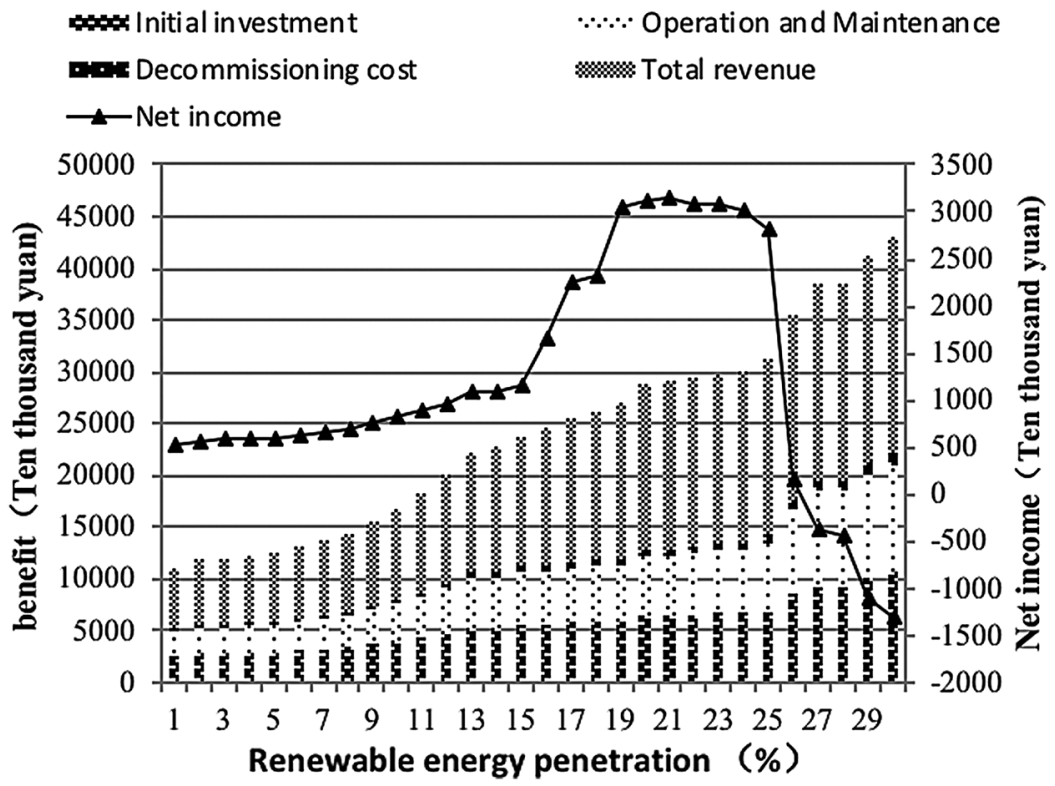

Figure 4: Cost-benefit Scenarios for scenario 2 with different permeability

In order to ensure the quality and reliability of power supply, assume a maximum renewable energy penetration of 30 percent, at the permeability range of $[0 \%, 30 \%]$, the cost and benefit of different renewable energy penetration rates under three conditions can be obtained, as shown in Figs. 3-6:

According to Figs. 3-6, as the penetration rate of renewable energy increases, the initial investment cost, operation, and maintenance cost and decommissioning disposal cost all rise under the above three scenarios. The increase in reserve capacity causes an increase in initial investment costs. In contrast, the increase of operation and maintenance cost is caused by the rise of equipment maintenance frequency and rush repair frequency produced by the random fluctuation of renewable energy output. Besides, it can be seen that under the three scenarios, the net income first slowly increases and remains positive. When it exceeds a certain boundary point, the distribution network's net income declines and turns from positive to negative. In Scenario 1, when the penetration rate of renewable energy exceeds $26 \%$, the net income 


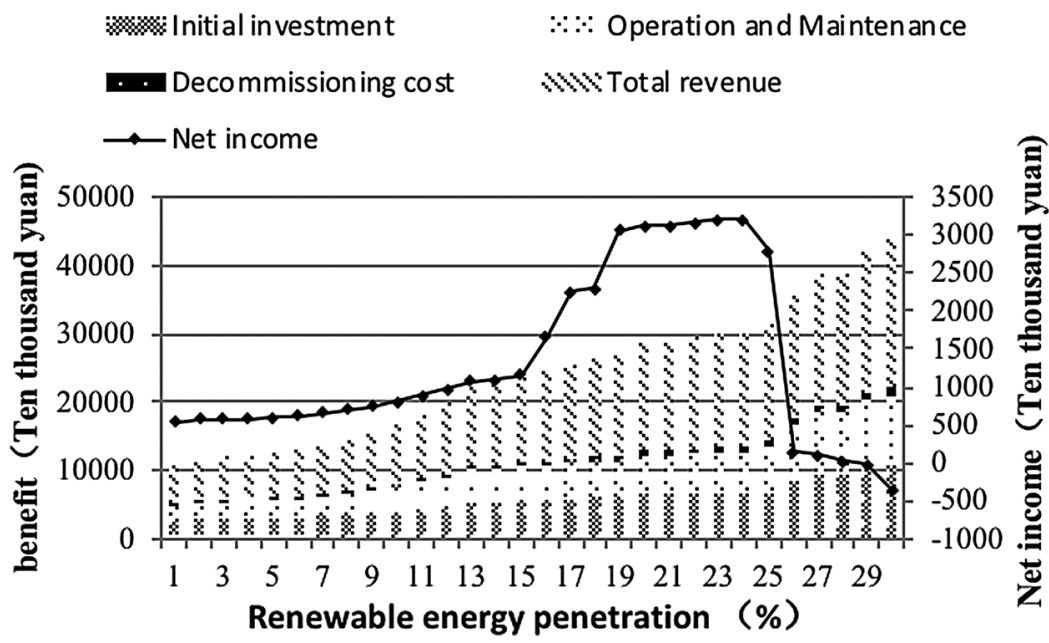

Figure 5: The cost-benefit situation of Scenario 3 with different permeability

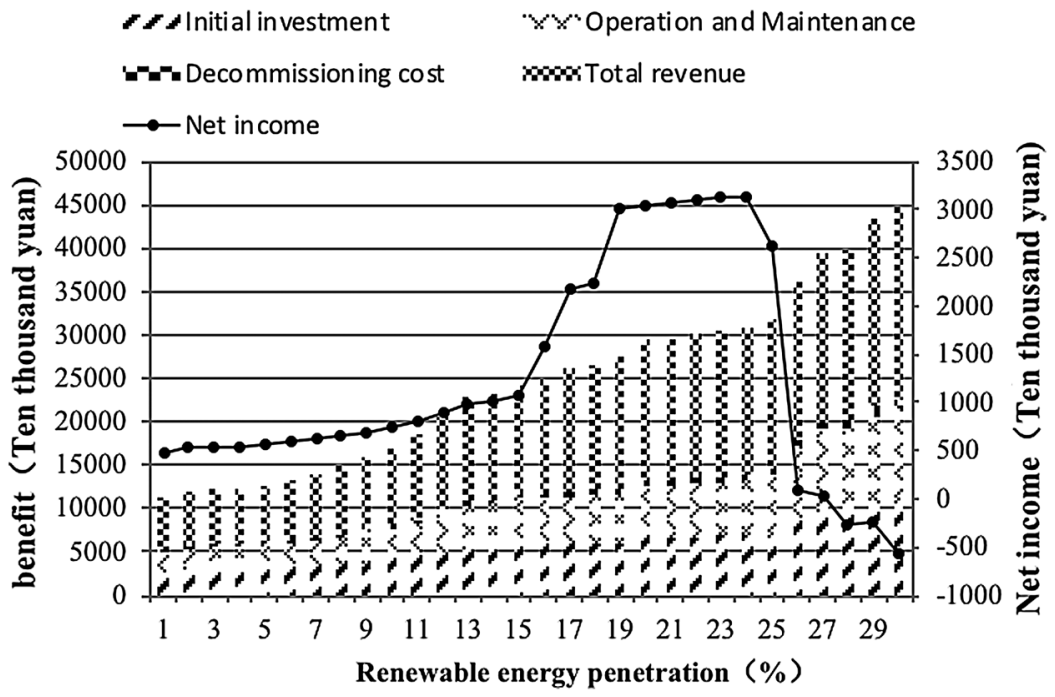

Figure 6: Scenario 4 cost-benefit situation at different penetration rates

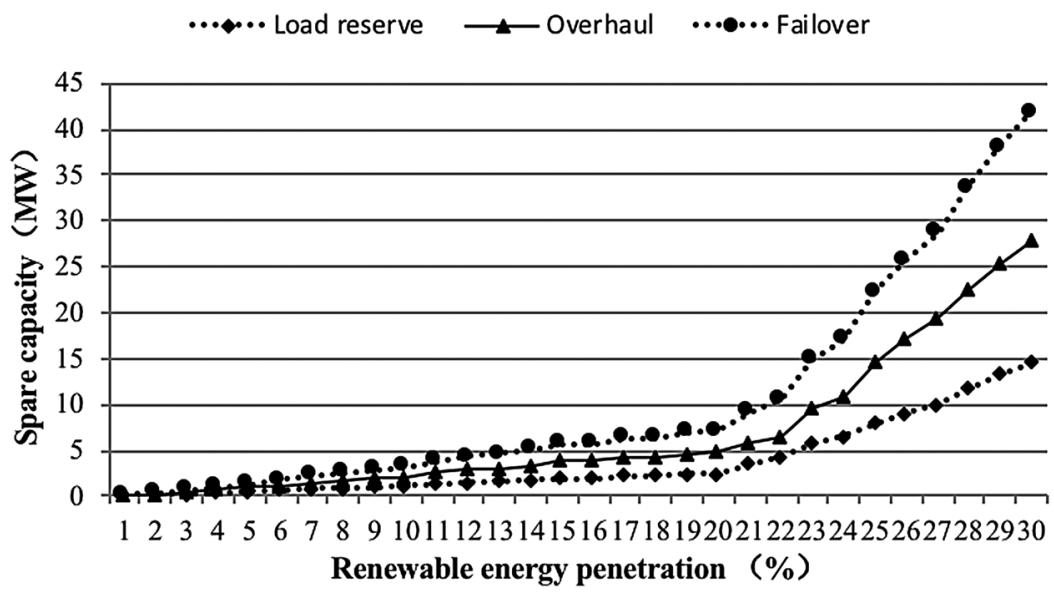

Figure 7: Reserve capacity setting of Scenario 1 at different permeability 


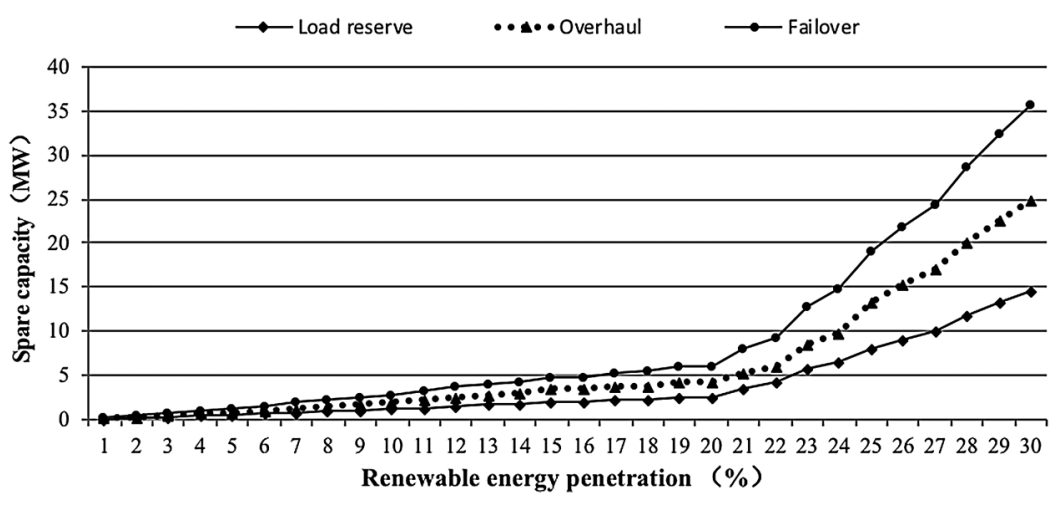

Figure 8: Reserve capacity setting of Scenario 2 at different permeability

decreases from 16.31 million yuan when the penetration rate is $25 \%$ to -10.77 million yuan. In Scenario 2, when the penetration rate reaches $27 \%$, the net income drops from 1.42 million yuan at $26 \%$ to -3.83 million yuan. The transition point of Scenario 3 is $29 \%$, from 150,000 yuan at 28:00 to $-280,000$ yuan. The transition point of Scenario 4 is $28 \%$, which drops from 170,000 yuan at $27 \%$ to -1.67 million yuan. Therefore, the higher the penetration rate of renewable energy is, the better. Only when the optimal penetration rate is reached can the net income of the distribution network be guaranteed.

Comparing the three scenarios above, we can see that the net income of situation 3 is the largest, and that of Scenario 1 is the smallest. That is to say, when wind power, photovoltaic, and thermal power infiltrate into the grid at the same time, the net profit is the largest compared with that of thermal power and photovoltaic power alone.

Through the model solving algorithm, the optimal solution of the model under three different scenarios can be obtained, and the details are shown in Tab. 2:

Table 2: Optimal solutions for different scenarios

\begin{tabular}{llll}
\hline The optimal solution & Scenario 1 & Scenario 2 & Scenario 3 \\
\hline Maximum net income (Ten thousand yuan) & 2140.79 & 3082.13 & 3214.09 \\
Optimum permeability (\%) & 19.02 & 21.45 & 24.53 \\
\hline
\end{tabular}

(3) The influence of different renewable energy penetration on distribution network

The reserve capacity Settings of the above three scenario distribution networks are shown in Figs. 7-10:

As can be seen from Figs. 7-10, with the increase in the penetration rate of renewable energy, load reserve, maintenance reserve, and accident reserve all increase in the four scenarios, and under the four scenarios, accident reserve $>$ maintenance reserve $>$ load reserve. Since the size of the accident reserve and maintenance reserve depends on the deviation of the wind power output and the photovoltaic output forecast and their respective reserve capacity coefficients, when the wind power output and photovoltaic output forecast deviations are certain, the accident reserve and the repair reserve are only related to the reserve capacity coefficient, and To ensure the stability of power supply and reduce the number of power outage accidents, the accident reserve factor $>$ maintenance reserve factor $>$ load reserve factor, so in four cases, accident reserve $>$ maintenance reserve $>$ load reserve. Among them, when the penetration rate of renewable energy is in the range of $[0 \%, 19 \%]$, the reserve capacity of Scenario 1 increases at a lower rate. In the range of $[19 \%, 30 \%]$, the reserve capacity of Scenario 1 starts Large speed increase; for 


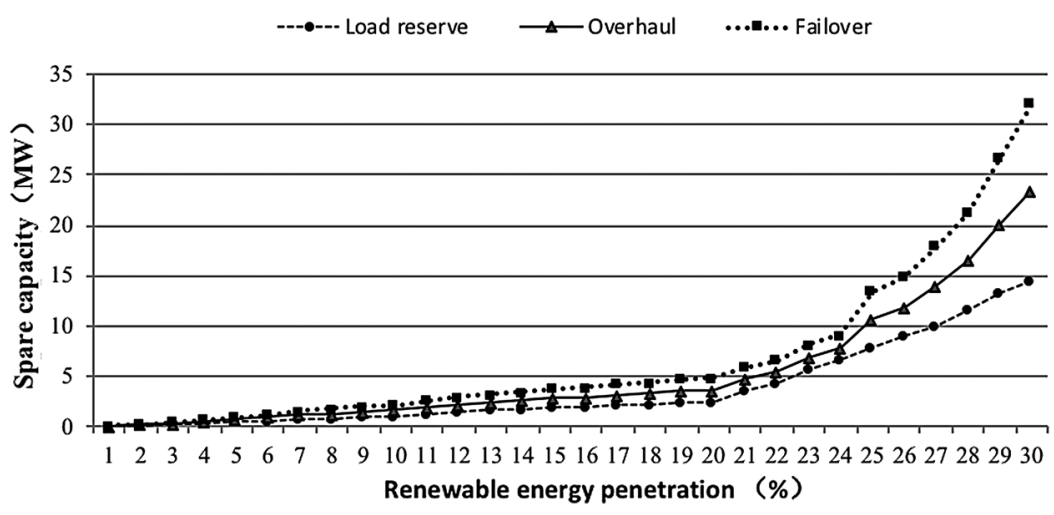

Figure 9: Reserve capacity setting of Scenario 3 at different permeability

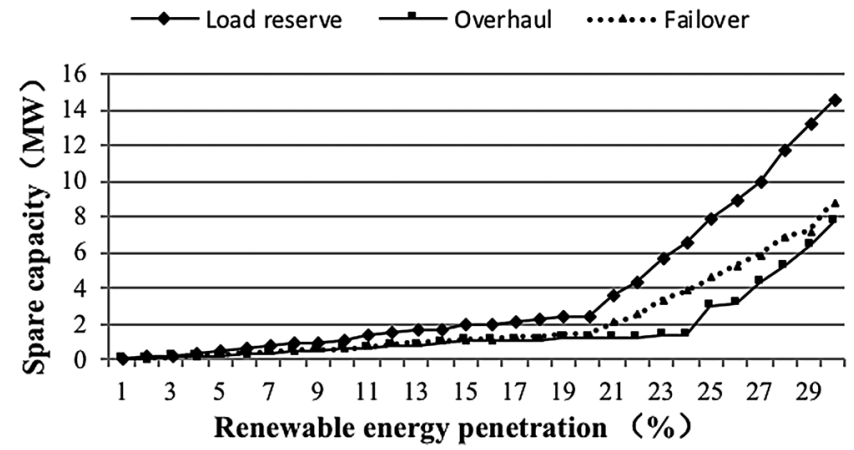

Figure 10: Scenario 4 reserve capacity settings under different penetration rates

Scenario 2, when the renewable energy penetration rate is in the range of $[0 \%, 21 \%]$, its reserve capacity growth rate is low, and in the range of $[19 \%, 30 \%]$, its reserve capacity growth rate Larger; Scenario 3's lower growth rate and larger interval are [0\%, 24\%], [24\%, 30\%]; Scenario 4's lower growth rate and larger interval are $[0,22 \%],[22 \%, 30 \%]$. As the penetration rate of renewable energy increases, the growth rate of reserve capacity under the four scenarios increases first and then decreases, This is because the penetration of renewable energy gradually increases beyond a certain percentage, which has a great impact on the stability of the system. It is necessary to continuously increase the value of various backup capacities to maintain system stability.

At the same time, based on the same renewable energy penetration rate, the maintenance reserve and accident reserve capacity of Scenario 3 is the minimum, while the maintenance reserve and accident reserve capacity of situation 1 is the maximum. When the penetration rate of renewable energy is $20 \%$, the maintenance standby capacity and emergency standby capacity of Scenario 1 are $2.28 \mathrm{mw}$ and 2.35 mw, respectively. In situation 2, the maintenance standby capacity and emergency standby capacity are $1.76 \mathrm{mw}$ and $1.81 \mathrm{mw}$, respectively. The reserve capacity of Scenario 3 is $1.17 \mathrm{mw}$ and $1.21 \mathrm{mw}$, respectively. This is because, in Scenario 3, wind power, photovoltaic and thermal power can be connected to the grid at the same time to take advantage of the wind-solar complementary characteristics and reduce part of the emergency reserve and maintenance reserve. Besides, compared with Scenario 3, Scenario 4's maintenance reserve and accident reserve capacity are larger than Scenario 3's reserve capacity. Taking renewable energy penetration rate of $20 \%$ as an example, Scenario 4's maintenance reserve and accident reserve are 1.29 MW, 1.45 MW; this is because Scenario 4 has a higher penetration 
rate of renewable energy than Scenario 3. The penetration rate of renewable energy is high, and higher reserve capacity is required to maintain the system's stable operation.

\section{Conclusion}

In this paper, the full cost-benefit model of distribution network under renewable infiltration is proposed. The optimization model of the technical transformation of the distribution network is constructed based on the comprehensive income of distribution network and the maximum penetration rate of renewable energy. Finally, taking a distribution network as an example, the influence of different renewable energy gridconnection scenarios on the total cost and benefits of the distribution network is discussed. Based on the case study, the following conclusions are drawn:

1. Compared with the grid-connection of only one kind of renewable energy, the parallel gridconnection of wind power, photovoltaic and thermal power can not only reduce the setting of standby capacity for maintenance accidents in the distribution network but also reduce the cost of operation and maintenance in the process of technical transformation of the distribution network.

2. When renewable energy is connected to the grid, its net income tends to increase first and then decrease. When the penetration rate of renewable energy is large, its net income is even negative. Therefore, the grid should reasonably plan the connection rate of renewable energy.

3. Compared with the grid-connection of only one renewable energy source, the optimal gridconnection permeability of wind power and photovoltaic is higher than the optimal gridconnection permeability of only one renewable energy source.

Acknowledgement: The completion of this paper has been helped by many teachers and classmates. We would like to express our gratitude to them for their help and guidance.

Funding Statement: This research was funded by The National Natural Science Foundation of China "Research on the Mechanism Design and Simulation Model for Reducing Energy Dissipation of Clean Energy in China" (71573084).

Conflicts of Interest: The authors declare that they have no conflicts of interest to report regarding the present study.

\section{References}

1. Zhang, Y., Chen, Q. X., Xia, Q., Shi, L., Yu, L. et al. (2020). Active distribution network cost allocation method based on distribution factor method. China Electric Power, 53(4), 13-21.

2. Wang, Y. L., Li, M., Tian, C. Z., Song, S. S., Zhang, F. L. et al. (2018). Research on distribution network engineering cost supervision and management and optimization problems - analysis based on improved earned value method. Price Theory and Practice, 8, 86-89.

3. Xu, Y. Q., Liu, Y., Xie, Q. (2018). Based on whole life cycle cost of reactive power distribution network planning study. Power System Protection and Control, 46(11), 30-36.

4. Fang, Y., Xi, P. Y., Shen, Q. B., Wang, L., Chen, G. J. et al. (2019). Quantitative analysis of the impact of renewable energy penetration rate taking into account the cost-effectiveness of source-network-charge. Smart Power, 47(5), $43-50+58$.

5. Wu, Z. Q., Teng, H., Li, J. K., Li, X. S., Liang, M. K. (2017). Research on the marginal capacity cost of nodes in distribution networks. Science Technology and Engineering, 17(8), 176-181.

6. Wang, Y. L., Wang, X. H., Wang, S., Yu, H. Y., Zhang, F. L. et al. (2020). Research on the cost allocation method of power grid operation and maintenance based on the reform of power transmission and distribution price. Power System Technology, 44(1), 332-339.

7. Roustaei, M., Sheikh-El-Eslami, M. K., Seifi, H. (2014). Transmission cost allocation based on the users' benefits. International Journal of Electrical Power and Energy Systems, 61, 547-552. DOI 10.1016/j.jiepes.2014.03.053. 
8. Zheng, Z., Zhou, Y., Wang, Q., Wang, J., Huang, Y. F. (2019). Research on the optimization of transformer lifecycle cost based on rhododendron algorithm. Power System Protection and Control, 47(8), 49-55.

9. Lv, X. F., Zhou, J., Jiang, C. W. (2016). Optimization of bilateral reserve capacity of power system based on uncertainty of renewable energy. Electric Power Construction, 37(4), 16-21.

10. Wu, J., Xue, Y. S., Shu, Y. B., Xie, D. L., Song, X. F. (2019). Optimization of power system abundance under large-scale renewable energy access (ii) coordinated optimization of multi-level reserve. Automation of Power Systems, 43(10), 19-28.

11. Li, T., Xu, Y., Chen, J., Wang, K. (2020). Optimal allocation of energy storage in microgrid with lifetime costs and benefits. Proceedings of the CSU-EPSA, 32(3), 46-51+58.

12. Lu, G. F., Ou, J. L., Jiang, Y. P., Zhang, S., He, Y. L. (2020). Study on dynamic reactive power cost optimization of power systems including wind farms in power market. Journal of University of Electronic Science and Technology of China, 49(1), 110-116.

13. Song, C. L., Liu, D. C., Wu, J., Dong, F. F., Zhao, Y. J. et al. (2013). Economic evaluation method of grid planning based on differentiated life-cycle cost. Power System Technology, 5(7), 1849-1855.

14. Zhu, J. Z., Zhang, Y., Liang, W. J., Wang, G. Q. (2017). A plan-oriented method for evaluating the total life-cycle safety and efficiency cost of power gri. Proceedings of the Chinese Society for Electrical Engineering, 37(23), 6768-6779+7068.

15. Jin, S. P., Fang, F., Zhu, Z. Y., Liu, J. Z. (2020). Game analysis of micro grid capacity allocation with power shortage rate constraint in different investment models. Electric Power, 1-9. https://kns-cnki-net.webvpn.ncepu. edu.cn/kcms/detail/11.3265.TM.20200225.1835.004.html.

16. Cui, Y., Yang, Z. W., Zhang, J. T., Wang, M. C., Yan, G. G. (2019). Combined wind power, photovoltaic and photothermal combined output scheduling strategy with comprehensive cost. High Voltage Engineering, 45(1), 269-275.

17. Su, W. H., Guan, J., Yang, Y. J., Li, Q. Y., Gao, C. W. (2014). Sensitivity analysis model for whole-life cycle cost grid planning. Electric Power, 47(11), 127-133.

18. Peng, C. H., Liu, B., Sun, H. J. (2020). Robust environmental and economic scheduling of power systems based on classified uncertainty sets. Proceedings of the CSEE, 40(7), 202-2212+2399.

19. Zhang, Y. Y., Li, L., Liu, X. M. (2019). Comprehensive evaluation method of operational benefits of integrated energy systems with uncertainty. Renewable Energy Resources, 2019, 37(11), 1671-1678.

20. Jiang, L., Zheng, Q. W., Wang, F., Ji, M. L., Liu, J. et al. (2020). Expansion planning of transmission network considering direct load control and wind power uncertainty. Power System Protection and Control, 48(3), 138-146.

21. Zhu, Y., Shao, B., Liu, Y. F., Zhou, Y., Li, Y. X. (2019). A study on the optimal allocation model of distributed energy system-a case study of the new countryside in Guan Zhong. Acta Energiae Solaris Sinica, 40(9), 25472553. 